time and treatment effects.) No systematic differences attributable to age or sex were noted, however.

On the other hand, the direct-choice procedure in Stage 3 resulted in a decided and consistent preference for hoarding sucrose $(p<.05$, Wilcoxon test). From Stages 1 and 2, when only one material was available, the sucrose-to-chow ratio was approximately $4: 3$. With both materials presented simultaneously, the ratio increased to $2: 1$. The total number of pellets hoarded did not change from Stage 2; rather, the higher ratio resulted from a decrease in chow hoarding and a compensatory increase in sucrose hoarding. These results clearly support the hypothesis that sucrose would be preferred as hoarding material, even though it was not available as a food source.

We have assumed that taste alone was responsible for the sucrose preference; however, the influence of other characteristics of the pellets cannot be ruled out. Other sensory qualities, visual or olfactory, remain to be tested. Nonedible material of the same size and shape (wooden beads, for example) should also be compared. Nevertheless, the results show that hoarding behavior in the hamster is selective with respect to the stimulus objects. No reference need be made to previous or present deprivation, leaming, body states, emotion, or the like.

We present this study not only for its own interest but also as an argument for the value of studying stimulus control of hoarding. The availability of any material preferred to lab chow may elicit a high rate of activity, even under conditions that had previously been considered unfavorable. Moreover, allowing a direct preference to be shown will be more revealing than absolute measures taken from different animals at different times. In view of the current surge of interest in animal behavior among psychologists, we invite a new look at the problem of hoarding behavior.

\section{REFERENCES}

BINDRA, D. The nature of motivation for hoarding food. Journal of Comparative \& Physiological Psychology, 1948a, 41, 211-218. BINDRA, D. What makes rats hoard? Journal of Comparative \& Physiological Psychology, 1948b, 41, 397-402.

CARPENTER, J. A. Species differences in taste preference. Journal of Comparative \& Physiological Psychology, 1956, 49, 139-144.

HUNT, J. McV., \& WILLOUGHBY, R. R. The effect of frustration on hoarding in rats. Psychosomatic Medicine, 1939, 1, 309-310.

LICKLIDER, L. D., \& LICKLIDER, J. C. R. Observation on the hoarding behavior of rats. Journal of Comparative \& Physiological Psychology, 1950, 43, 129-134.

MCCORD, F. The effect of frustration on hoarding

in rats. Joumal of Comparative Psychology, $1941,32,531-541$.

MORGAN, C. T. The hoarding instinct. Psychological Review, 1947, 54, 335-341.

PFAFFMANN, C. Taste, its sensory and motivating properties. American Scientist, $1964,52,187-206$.

ROSS, S., \& SMITH, W. I. The hoarding behavior of the mouse: II. The role of deprivation, satiation, and stress. Journal of Genetic Psychology, 1953, 82, 299-307.

SMITH, W. I. \& ROSS, S. The hoarding behavior of the mouse: $I$. The role of previous feeding experiences. Journal of Genetic Psychology, $1953,82,279.297$.

ERRATUM

MILES, C. G. A demonstration of overshadowing in operant conditioning. Psychonomic Science, 1969, 16 (3), 139-140.-Page 139, under Procedure, the sentence beginning "Otherwise the trial ended-" should read as follows: "Otherwise the trial ended, without reinforcement, after 8 sec."

\title{
Failure of exogenous ACTH to influence the acquisition or reversal of a spatial discrimination in rats
}

PATRICIA ANN BEATTY, ${ }^{1}$ TIMOTHY H. STOLLE, and WILLIAM W. BEATTY, , 2 University of Wisconsin, Madison, Wis. 53706

Injections of ACTH, under conditions that had previously been shown to facilitate acquisition of a shuttle-avoidance response, had no effect on the acquisition or reversal of a spatial discrimination. The failure of ACTH to affect performance in an appetitive situation argues against interpretations that ACTH facilitates acquisition and prolongs extinction of avoidance behavior by improving the efficiency of biochemical processes underlying memory.

In a recent series of studies, ${ }^{3}$ it was found that exogenous elevation of circulating ACTH levels facilitated the acquisition of a two-way shuttle avoidance response. Injections of $\mathrm{ACTH}$ have also been shown to prolong extinction of both an active- (e.g., de Wied, 1966; Murphy \& Miller, 1955) and a passive-avoidance response (Levine \& Jones, 1965). The effects of ACTH on active-avoidance behavior appear to be independent of adrenal stimulation (de Wied, 1966). ${ }^{3}$

De Wied \& Bohus (1966) have suggested that ACTH may increase resistance to extinction by improving the efficiency of biochemical processes underlying memory consolidation. Such an explanation might also account for the improvement in avoidance performance during acquisition tests. If the memory consolidation interpretation is correct, ACTH would be expected to improve performance in a nonaversive situation as well. To test this hypothesis, the effects of ACTH on the acquisition and reversal of a spatial discrimination were investigated.

\section{METHOD}

Twenty-two Holtzman albino rats, $270-290 \mathrm{~g}$ at the start of the experiment, 
Table 1

Mean Performance During Acquisition and Reversal

\begin{tabular}{|c|c|c|c|c|c|c|c|c|c|c|c|}
\hline \multirow[b]{3}{*}{ Group } & \multicolumn{4}{|c|}{ Criterion Measures } & & \multicolumn{6}{|c|}{ Latency Data* } \\
\hline & \multicolumn{2}{|c|}{ Original Learning } & \multicolumn{2}{|c|}{ Reversal Learning } & & \multicolumn{3}{|c|}{ Original Learning } & \multicolumn{3}{|c|}{ Reversal Learning } \\
\hline & $\begin{array}{c}\text { Days to } \\
\text { Criterion }\end{array}$ & $\begin{array}{l}\text { Errors to } \\
\text { Criterion }\end{array}$ & $\begin{array}{l}\text { Days to } \\
\text { Criterion }\end{array}$ & $\begin{array}{l}\text { Errors to } \\
\text { Criterion }\end{array}$ & & $\begin{array}{l}\text { First } \\
\text { Third }\end{array}$ & $\begin{array}{c}\text { Middle } \\
\text { Third }\end{array}$ & $\begin{array}{c}\text { Last } \\
\text { Third }\end{array}$ & $\begin{array}{l}\text { First } \\
\text { Third }\end{array}$ & $\begin{array}{c}\text { Middle } \\
\text { Third }\end{array}$ & $\begin{array}{l}\text { Last } \\
\text { Third }\end{array}$ \\
\hline $\begin{array}{l}\text { ACTH } \\
n=11\end{array}$ & 7.73 & 40.36 & 11.18 & 84.00 & $\begin{array}{r}\text { Correct } \\
\text { Incorrect }\end{array}$ & $\begin{array}{l}5.14 \\
6.06\end{array}$ & $\begin{array}{l}3.11 \\
4.00\end{array}$ & $\begin{array}{l}2.13 \\
3.74\end{array}$ & $\begin{array}{l}5.86 \\
2.58\end{array}$ & $\begin{array}{l}2.85 \\
2.86\end{array}$ & $\begin{array}{l}1.97 \\
2.44\end{array}$ \\
\hline $\begin{array}{l}\text { Placebo } \\
n=10\end{array}$ & 8.90 & 50.60 & 13.40 & 96.30 & $\begin{array}{r}\text { Correct } \\
\text { Incorrect }\end{array}$ & $\begin{array}{l}7.60 \\
7.34\end{array}$ & $\begin{array}{l}3.12 \\
3.68\end{array}$ & $\begin{array}{l}2.05 \\
3.88\end{array}$ & $\begin{array}{l}3.80 \\
2.68\end{array}$ & $\begin{array}{l}2.45 \\
2.47\end{array}$ & $\begin{array}{l}1.76 \\
2.45\end{array}$ \\
\hline
\end{tabular}

* The latency data for each $S$ were vincentized into blocks of trials representing one-thind of the total trials required by the $S$ to meet the OL and $R L$ criteria. The median latency of correct and incorrect responses was computed for each $S$ for each third of trials. The means of the median latencies are given in the table.

were housed in individual cages in a temperature- and humidity-controlled room under continuous illumination. They received Purina lab chow pellets ad lib. Tests were conducted in a $Y$ maze with alleys made of aluminum and Lucite set $120 \mathrm{deg}$ apart. Each alley (i.d.: $32 \times 4 \times 5132$ in. high) was divided into an 113 -in. approach arm and a 20-in. goal box by a sliding Lucite door. Motor-driven dippers mounted in the end panel of each alley detivered $0.10 \mathrm{cc}$ of water when activated by $\mathrm{E}$. Response latencies were recorded automatically on a Standard electric timer which was activated when the start-box door was raised and terminated when $S$ entered either goal box to within 3 in. of the end panel

During the 5-day pretraining period, Ss were adapted to a $22 \frac{1}{2}-\mathrm{h}$ water-deprivation schedule, and shaped to drink from the dippers and shuttle from alley to alley. On Day 5 of pretraining, Ss were given six freeand six forced-choice trials to equate the frequency of reinforcement with left and right choices and to test for spatial preferences. Animals that exhibited a bias on free-choice trials were run against their bias during original learning. Experimental groups that received ACTH (Corticotrophin, Organon, 12 I.U daily) or an equal volume of gel placebo $4(0.15 \mathrm{cc})$ were formed in such a way as to equate the strength of bias between groups. Subcutaneous injections were given $1 \mathrm{~h}$ before the start of daily tests. Starting on Day 6, each $S$ received 15 daily trials using a noncorrection procedure. Original learning continued until $S$ met a criterion of at least 13 correct responses on 2 consecutive days. Reversal learning began the day after $S$ met criterion in $O L$ and continued until the same criterion had been attained. The data of one placebo $S$ were lost when the animal injured its foot during testing and would no longer approach the dipper.

\section{RESULTS}

Table 1 summarizes performance during $\mathrm{OL}$ and $\mathrm{RL}$. Although the ACTH group required slightly fewer days to meet criterion in both $\mathrm{OL}$ and RL, and made slightly fewer errors, these differences did not approach significance (all $p>.20$ ). It should be noted that the animal lost from the placebo group exhibited no spatial preference during pretesting. Since strength of preference was positively correlated with the length of training required to meet the OL criterion $(\mathrm{r}=.42, \mathrm{p}<.10)$, the average performance of the placebo and ACTH groups probably would have been more alike if the missing $S$ had completed training. The slightly poorer performance of the placebo group during RL was entirely due to one $S$ that required twice as many days to meet criterion, and made twice as many errors as any other animal.

Nevertheless, the ACTH group did tend to perform slightly better than the placebos, and question may be raised whether this difference would have attained statistical significance had the samples tested been larger. Obviously, this question cannot be answered directly. However, in a study of comparable size, 3 in which ACTH was found to facilitate avoidance behavior, the treatment effect accounted for $8.4 \%$ of the variance (Hays, 1963), while in the present study, the ACTH effect accounted for less than $1 \%$ of the variance in the analyses of each of the learning measures. Thus, it seems unlikely that ACTH has any appreciable influence on the acquisition or reversal of a spatial discrimination.

ACTH also failed to affect speed of responding in either $\mathrm{OL}$ or $\mathrm{RL}$. Although latencies decreased with training during OL $(F=34.62, \mathrm{df}=2 / 38, \mathrm{p}<.01)$ and were shorter on trials on which a correct choice was made $(F=6.23, \mathrm{df}=1 / 19, \mathrm{p}<.05)$, neither the main effect of drug treatment nor interactions with thirds of training or correctness of choice attained significance ( $p>$.05). During RL, both ACTH and placebo groups showed an initial increase in latency of correct response followed by a decline with continued training, but again there were no reliable differences due to hormone treatment.

\section{DISCUSSION}

The failure of ACTH to affect either choice or speed measures during the acquisition and reversal of a spatial discrimination suggests that its effects may be limited to aversively motivated situations. Levine \& Jones (1965) also reported preliminary evidence that $\mathrm{ACTH}$ failed to influence extinction of an appetitively motivated bar-press habit. Taken together these findings raise serious doubts about the validity or at least the generality of the "memory consolidation" interpretation of the effects of ACTH on avoidance behavior. In the absence of evidence that ACTH affects appetitively motivated behavior, a more detailed examination of the behavioral conditions under which ACTH influences responding to aversive stimuli would seem to be the most productive research strategy.

\section{REFERENCES}

HAYS, W. L. Statistics for psychologists New York: Holt, Rinehart, \& Winston, 1963.

LEVINE, S., \& JONES, L. E. ACTH and passive avoidance conditioning. Journal of Comparative \& Physiological Psychology, 1965, 59, 357-360.

MURPHY, J. V., \& MILLER, R. E. The effect of adrenocorticotrophic hormone (ACTH) on avoidance conditioning in the rat. Journal of Comparative \& Physiological Psychology, $1955,48,47-49$.

de WIED, D. Inhibitory effect of ACTH and related peptides on extinction of conditioned avoidance behavior in rats. Proceedings of the Society for Experimental Biology and Medicine, $1966,122,28-32$

de WIED, D. \& BOHUS, B. Long term and short term effects on retention of a conditioned avoidance response in rats by treatment with long acting pitressin and Q-MSH. Nature, 1966, $212,1484-1486$.

\section{NOTES}

1. Now at North Dakota State University, Fargo, N. Dak. 58102.

2. NIH Predoc toral Research Fellow.

3. Beatty, P. A., Beatty, W. W., Bowman, R.E., \& Gilchrist, J. C. The effects of ACTH, adrenalectomy, and dexamethasone on the acquisition of an avoidance response in rats, in preparation.

4. Gel placebo was generously supplied by the Organon Co., West Orange, N.J. 07052. 